\title{
Criminalizar al rojo. La represión al movimiento obrero en los informes de 1934 sobre la Sección Especial
}

\author{
Mercedes F. López Cantera \\ (UBA)
}

El fenómeno del anticomunismo encontró en el caso argentino su desarrollo y consolidación entre las décadas de 1920 y 1940. Si bien podríamos pensar los años 20 como un período formativo en el que los nacionalistas, los conservadores y la Iglesia comenzaron a señalar al elemento comunista como uno de sus enemigos políticos por excelencia a nivel nacional e internacional, fue en los años 30 cuando el pensamiento anticomunista halló sus características elementales. Esto ha podido observarse sobre todo en la literatura nacionalista reaccionaria que en esa década tuvo un despliegue destacable. Sin embargo, existió otro escenario en el que el anticomunismo no sólo se manifestó sino que tomó una forma material concreta: la represión politica ejercida por el Estado sobre la clase obrera.

Comprendiendo el anticomunismo como un objeto complejo, tanto por los actores que lo manifestaron como las variables que el mismo fue adquiriendo a lo largo de su historia, consideramos pertinente señalar en él dos dimensiones, una ideológica y una práctica. En lo que refiere a la primera, en la Argentina de entreguerras se manifestó entre los nacionalistas reaccionarios, el ámbito católico y los conservadores. En este trabajo nos abocaremos a la segunda, expresada en la represión que el Estado llevó a cabo durante los años 30, una década que consideramos fundacional para esta dimensión práctica.

El Estado argentino de aquellos años hizo presente entre sus preocupaciones la existencia de una "cuestión comunista", que durante la restauración conservadora iniciada con la presidencia de Agustín P. Justo (1932-1938) estuvo atravesada por la conflictividad social consecuente a la crisis y cambios económicos posteriores a 1929. La clase obrera fue la protagonista de ese estallido. Los trabajadores se encontraban transitando aún un ciclo de repliegue abierto con la imposición de la dictadura uriburista (1930-1932), avanzando en la reorganización 
del movimiento obrero, emprendiendo nuevas protestas dentro de las cuales algunas organizaciones comenzaron a hacer sentir su presencia, como el Partido Comunista (PC). Éste se encontraba transitando su etapa de "clase contra clase", estrategia política impulsada por la Comintern en 1928, que planteaba la intransigencia revolucionaria (la no asociación con ninguna tendencia de izquierda, ni socialista ni anarquista), constituyendo un frente combativo, extremo y sectario, que sostuvo hasta 1935.

La izquierda revolucionaria se hizo presente en el movimiento sindical de esos años. Representativo de ello fue el intenso ciclo de huelgas de 1932 a 1935, entre las que podemos destacar la de los obreros petroleros de Comodoro Rivadavia en abril-junio de 1932; la de los trabajadores de la Federación Obrera de la Industria de la Carne (FOIC), en mayo de 1932, sin apoyo ni de la CGT ni de la Federación Obrera Regional Argentina (FORA), como la de los petroleros; las huelgas generales de diciembre de 1932 y agosto de 1933, convocadas por la FORA con la participación del Comité de Unidad Sindical Clasista (CUSC), organización creada por el mismo PC para contrarrestar el poder de la Confederación General del Trabajo (CGT); la de los trabajadores del algodón en Chaco (1934 a 1936); la de la madera, liderada por el Sindicato Único de Obreros de la Madera (SUOM), en junio y julio de 1934; y la de los trabajadores del vestido, entre septiembre y octubre de $1934{ }^{1}$

Frente al reclamo y la protesta, el Estado en manos conservadoras respondió con represión, aunque no con la modalidad de los años de Uriburu. Las características que ésta adquirió durante el gobierno de Justo significaron un antes y un después en la estructura represiva del Estado, en la que el aparato policial jugó un papel decisivo (Kalmanowiecki, 1991). En 1934, un hecho particular evidenció ese proceso. A mediados del mismo representantes del Partido Socialista (PS) exigieron en la Honorable Cámara de Diputados de la Nación (HCD) la interpelación del entonces Ministro del Interior, Leopoldo Melo -uno de los fundadores de la Unión Cívica Radical Antipersonalista, desde donde apoyó la candidatura de Agustín P. Justo en 1931-acerca de las actividades desplegadas por la llamada Sección Especial de Represión al Comunismo, que adelante denominaremos SERC, dependencia de la Policía de la Capital. ${ }^{2}$ La actuación de estos diputados fue motivada por

1. Para una mayor comprensión sobre la situación del movimiento obrero en los años 30 se sugieren los trabajos de Matshushita, 1983; Korzeniewicz, 1993; Del Campo, 1983; Horowitz, 2001; Iñigo Carrera, 2000, 2002; Camarero, 2007; Ceruso, 2010.

2. La Policía de la Capital fue el primer órgano de seguridad interna tras la consolidación del Estado Nacional. Organizada entre 1880 y 1885, si bien su jurisdicción fue la Capital Federal, funcionó como "policía de Estado" hasta que fue absorbida por la Policía Federal Argentina (creada en 1943) en enero de 1945. 
las sucesivas denuncias al sistema judicial y a la prensa sobre la detención y aplicación de torturas a militantes de izquierda, principalmente obreros, que venían aconteciendo desde el retorno conservador. E1 PS logró que el ministro en cuestión elevara un informe que explicara y justificara las actividades de la SERC. En contraposición, el organismo Socorro Rojo Internacional (SRI) -dedicado a la defensa de detenidos y perseguidos políticos ${ }^{3}$ redactó otro documento ese mismo año que también elevó a Diputados, donde se detallaban los casos de abusos de la policía contra los militantes obreros negados en el informe del ministro.

El año 1934 y la discusión por la existencia y actuación de la SERC constituyeron un hito en el anticomunismo argentino de la década del 30. Nos interesa centrarnos en el análisis de ese debate para analizar de qué manera el Estado fue desarrollando una política represiva con características particulares y si ello significó o no una sistematización de la misma. Por otra parte, cabe preguntarnos si el origen de esa especificidad se debió al conocimiento que el aparato estatal obtuvo a partir del espionaje e investigación realizados sobre quienes eran objeto de control: las tendencias combativas del movimiento obrero. En el examen del llamado "Informe Melo" y del folleto-informe del SRI, observaremos cómo esas organizaciones obreras dieron lugar a una forma especifica de control por parte del Estado que formó parte de la denominada "cuestión comunista", lo que nos lleva a preguntarnos si ello implicó la criminalización de determinado tipo de militante político para lograr el disciplinamiento buscado.

Las fuentes que utilizamos poseen una cualidad distintiva: el informe del ministro Melo sobre la SERC no ha sido trabajado por la bibliografia del período, mientras que el folleto Bajo el terror de Justo, si bien es citado por algunos autores, no fue analizado en sí mismo. Cabe señalar que la interpelación al ministro no es referida en ningún trabajo que haya abordado los temas pertinentes a los años en cuestión. Además de estos materiales, nos interesa situarlos en el contexto de la prensa del momento, tanto la perteneciente al movimiento obrero como la de difusión comercial. Finalmente, con este trabajo pretendemos contribuir al estudio de la historia politica del país en general, del desarrollo del movimiento obrero y de la acción represiva estatal, cuestiones hilvanadas por medio de nuestro más importante objeto de análisis: el anticomunismo.

3. Creado en 1922 por la III Internacional, siendo en 1926 la fundación de su sección argentina, el SRI fue una entidad dedicada a la denuncia de la represión política y un órgano de asistencia legal para la liberación de militantes detenidos. 


\section{Una "cuestión comunista" para el ciclo conservador}

La mayoría de los autores dedicados a los años de entreguerras en Argentina mencionan la "cuestión comunista" y el anticomunismo como elementos dominantes y comunes en las variadas corrientes de derechas de esa etapa. Sin embargo, con algunas excepciones, esta característica ha sido poco explorada o subsumida a problemáticas como el componente antidemocrático o a las cercanías de esas derechas con el fascismo (Rock, 1993; Devoto, 2002; Finchelstein, 2010). Algunos trabajos, aquellos en los que el movimiento obrero es un actor ausente, llegan a plantear la existencia de un "anticomunismo sin comunismo", un temor sobredimensionado que actuó como motor político de los nacionalistas antiliberales y como "excusa" para la represión obrera (Rouquié, 1978; Zanatta, 1996). Al margen, existen investigaciones que sí incorporan al anticomunismo como un componente elemental en el pensamiento reaccionario del período, enfatizando que la principal problemática para las derechas era justamente la presencia de tendencias de izquierda en el movimiento obrero (McGee Deutsch, 2005; Lvovich, 2003).

De acuerdo a nuestro trabajo, la existencia de una "cuestión comunista" para el Estado de la restauración conservadora (1932-1943) se vinculaba al desarrollo de la "cuestión obrera". Desde el inicio de la posguerra, sectores de las clases dominantes, miembros de la Iglesia católica, nacionalistas y nacionalistas católicos, comenzaron a hacer referencia al retorno de una "cuestión social". Ello indicaba la conflictividad social resultante de los ciclos de crisis económicas (Gran Guerra y posguerra, crisis de Wall Street) y los reclamos o problemas que la clase trabajadora presentaba en sus condiciones de vida y de trabajo. En los años 20 la problemática que planteó el desarrollo de un movimiento obrero de izquierdas para esas expresiones reaccionarias generó una diversidad de discursos cuya pluralidad significó que ese enemigo comunista se tornara más difuso, derivando muchas veces en la idea de una amenaza hipertrofiada. Todo ello colaboró con la negación de la "cuestión comunista" de la década posterior. Los años 30 dieron otra materialidad al anticomunismo. Por un lado, la existente crisis económica provocó las más importantes tensiones entre el capital y el trabajo. Eso confluyó con la desmesurada represión de la dictadura de Uriburu (1930-1932) que llevó a que parte del movimiento obrero se replegara en la clandestinidad. Para el retorno "democrático" de 1932, las organizaciones politicas de la izquierda obrera comenzaron a manifestar su descontento por las consecuencias de la crisis y a reclamar por el reconocimiento de estructuras sindicales, llevando al planteo de nuevas tácticas politicas.

Frente a esta situación encontramos al gobierno de Justo embarca- 
do en la recuperación económica del país por medio de la intervención estatal. Su principal respaldo recaía en manos de la clase propietaria, terratenientes e industriales, al tiempo que contaba con el voto de confianza de los grupos nacionalistas, aún a pesar del recelo de éstos. ${ }^{4}$ Por otra parte, el presidente conservador no escatimó en acercamientos a la Iglesia; entre varios hitos de esa relación encontramos el apoyo y participación de éste en el Congreso Eucarístico Internacional de 1934. Esta red de legitimidad respaldaba a Justo pero no era suficiente para consolidar su poder político. Ello dependía principalmente de dar solución a la crisis económica, una preocupación que necesitaba del consenso y colaboración de la clase dominante al tiempo que resultaba imprescindible contar con una clase obrera no conflictiva.

Estos condicionantes fueron dando lugar al comienzo de una política de disciplinamiento que tuvo varios aspectos. En lo que refiere al Estado, la represión estuvo a la orden del día para controlar a aquellos trabajadores que promovieran la lucha. De ahí que la presidencia de Justo complejizara la represión que ya venía teniendo lugar desde Uriburu. La Sección Especial se convirtió en la piedra basal de esa política. La SERC fue fundada en 1931 por Carlos Rodríguez, y luego recreada y dirigida en 1932 por Federico Donadio, quien sería reemplazado al año por Joaquín Cusell. La misma dependía de la Sección de Orden Político (SOP) de la Policía de la Capital, conformada en la década de 1910 a fin de controlar todo tipo de acción política de los ciudadanos y residentes que fueran consideradas como un atentado al orden social. La Sección Especial formó parte de un conjunto de reformas que dotaron de mayores recursos a la Policia, la segunda transformación en importancia desde el proceso de profesionalización realizado por el coronel Ramón Falcón a principios de siglo. Durante ese gobierno tuvo lugar un recrudecimiento de la violencia estatal dentro del cual jugó un papel importante el aumento de las prácticas de espionaje que desde 1932 la SERC desarrolló con una finalidad represiva anticomunista (Caimari, 2012).

El "temor comunista" que nacionalistas, católicos y la clase dominante manifestaban desde hacía más de una década ahora se incluía dentro de la agenda del Estado. Justo y el brazo represivo conformado por su ministro Melo y los sucesivos directores de la Policía y la Sección Especial, plantearian la necesidad de combatir el "avance rojo" como un medio de control sobre la clase obrera. Pero ello presentaba un inconveniente: la propaganda política del justismo que enfatizaba el retorno a la "normalidad constitucional". Esa "normalidad", pregonada por el

4. "El general Justo y los conservadores", en La Nueva Republica (LNR), 2a. época, $\mathrm{n}^{\circ} 101,21 / 10 / 1931$, p. 1; "Justo no es el candidato del gobierno", LNR, 2a. época, $\mathrm{n}^{\circ} 120,2 / 11 / 1931$, p. 1 . 
presidente al inicio de su gobierno con la intención de diferenciarse de la dictadura de Uriburu, no podía contradecirse con medidas que atentaran visiblemente contra las garantías constitucionales. En este marco, el Estado debería desplegar una nueva modalidad de represión que oscilara dentro de marcos legales.

\section{Acción preventiva y "la desviación hacia el bandolererismo"}

En junio de 1934 se dieron a conocer públicamente denuncias contra la Sección Especial. El diario Crítica fue el primer medio en exponer testimonios sobre ello: se trataban de casos de tortura contra militantes, en su mayoria obreros, que habían sido detenidos por la Policia de la Capital. ${ }^{5}$ Los socialistas, desde La Vanguardia (en adelante, $L$ V), ya venían denunciando otros abusos de la policía en el marco de los dos estados de sitio $^{6}$ establecidos por Justo (el primero, desde diciembre de 1932 a mayo de 1933; el segundo, de diciembre de 1933 a julio de 1934). ${ }^{7} L V$ concluyó que ese marco legal daba lugar a la persecución política y no a la delictiva por parte de las autoridades, considerando que la llamada "represión al comunismo" permitía la violación de los derechos de los trabajadores y la persecución a sus organizaciones obreras. ${ }^{8}$ Esta posición del PS se inscribe en su tradición política de encarnarse como la "voz obrera" a nivel parlamentario. En lo que refiere a los años 30, fue ese partido el que elevó al Congreso Nacional cuestiones como el costo de vida y el reconocimiento sindical, así como las denuncias contra la represión.

El 25 de julio de 1934 Luis Ramiconi-diputado del PS por la Capital Federal de 1934 a 1938, Secretario General de la Federación Gráfica Bonaerense y miembro del Comité Central de la CGT para 1936-, solicitó

5. “Torturas terribles se aplican a los presos", en Crítica, año XXI, n 7249, 21/6/1934, p. 3; "Torturándolo con la máquina, dice el Dr. Gomila, hicieron confesar a un detenido delitos imaginarios", en Crítica, XXI, n 7251, 23/6/1934.

6. "El gobierno del general Justo y el derecho de reunión", $L V$, año XXXVIII, $\mathrm{n}^{\circ} 8946$, $2 / 3 / 1932$, p. 1 , y "Atenta al derecho de reunión el reciente edicto policial", $L V$, año XXXVIII, ${ }^{\circ}$ 8962, 18/3/1932, p. 1.

7. Existen en la bibliografia contradicciones respecto a esas fechas; la posición más acertada (seguida en este texto) la expresa Caimari gracias a la reconstrucción realizada por miembros del Archivo General de la Nación (Caimari, 2012: 94).

8. Ver $L V$, año XL, no 9618, 7/1/1934, p. 1, y $L V$, año XL, no 9625, 14/1/1934, pp. 1 y 3. También ver "Presos políticos y sociales", $L V$, año XL, $n^{\circ}$ 9679, 9/3/1934, pp. 1 y 2. 
al Poder Ejecutivo la presentación de informes sobre la Sección Especial. ${ }^{9}$ Se especificó que debían presentarse las razones que determinaron la creación de esa Sección, presupuestos y gastos, nómina de detenidos, procesados y puestos en libertad, y lo relativo a denuncias por torturas o malos tratos conferidos a los presos. Los motivos que esgrimió fueron que las acciones de la SERC eran propias de un estado de sitio, como la aplicación de censura contra parte de la prensa obrera que acusaban de "orientación comunista". El antecedente directo a ese tema había sido el cierre en 1932 durante el estado de sitio de dos periódicos del PC aparecidos en 1932; el primero y con causa judicial, Bandera Roja, y el segundo, Mundo Obrero, matutino del que llegaron a publicarse sólo veinte números.

La acusación de Ramiconi contra la SERC apuntaba al accionar erróneo de la misma, no necesariamente a su existencia en sí. Aludió que la Sección procedió contra obreros, militantes y estudiantes acusándolos "por delitos que no cometieron", posición reiterada por otro diputado socialista, Demetrio Buira (originario de La Pampa y vinculado a las Ligas Agrarias de esa región), y por $L V .{ }^{10}$ En respuesta a estos argumentos, el diputado por el Partido Demócrata Nacional Vicente Solano Lima justificó el accionar de la Sección: los militantes comunistas "avanzan para interponerse en todas las acciones legitimas de los grupos obreros". Sin embargo, apoyaba el pedido de informe a fin de conocer las razones de la creación de la SERC por el Poder Ejecutivo y comprender la conflictividad social existente. Finalmente, ante el reclamo socialista y el aval dado por los conservadores, el Congreso dio lugar al pedido de informe. El ministro Melo lo presentó el 8 de agosto, ${ }^{11}$ abordando los cuatro puntos solicitados por Ramiconi, junto a otro documento de carácter policial acerca de las acciones reprimidas.

Podemos indicar la presencia de dos ejes que atraviesan ese material por medio de los cuales se justificaba la actividad de la Sección. El primero es la preocupación expresada por el ministro como portavoz del gobierno acerca de las "nuevas formas" que las actividades ilícitas

9. Ramiconi, Luis, 25 de julio de $1934,29^{\circ}$ reunión, $20^{\circ}$ Sesión Ordinaria, Honorable Cámara de Diputados, Archivo Memoria legislativa de la HCD. La Prensa publicó el pedido de informes sin darle demasiada relevancia ("La Cámara de Diputados aprobó ayer varios pedidos de informes al Poder Ejecutivo e inició la consideración de otros asuntos", La Prensa, año LXV, n 23522, 26/07/1934, p. 9) mientras que La Nación no expresó registro del mismo.

10. "Aprobó la Cámara un pedido de informes sobre la Sección Especial de Represión al Comunismo", $L V$, año XLI, nº 9817, 26/7/1934, pp. 2 y 3.

11. Mensaje contestando el pedido de informes acerca de las razones que determinaron la creación en la Policía de la "Sección especial de represión contra el comunismo", Archivo de la HCD, legajo ${ }^{\circ} 115,8 / 8 / 1934$. 
tomaron en los últimos años, es decir, las iniciativas militantes de la clase obrera, incluidas dentro de la esfera delictiva como "acciones disolventes". El segundo eje toma como preocupación una de esas novedades: las estrategias de "ayuda jurídica" que los "delincuentes" desplegaban para su defensa. Así es como Melo caracterizó la ayuda legal realizada por abogados y organismos como el SRI.

En el primer folio del informe, el ministro Melo indicaba que el origen de la tendencia delictiva dentro del movimiento obrero se agudizó luego de finalizada la Primera Guerra Mundial, en particular tras el estallido de la Revolución Rusa. No era un análisis aislado, ya que esa misma conclusión era sostenida desde hacía más de una década por las corrientes del nacionalismo reaccionario (McGee Deutsch, 2005). En relación a los años inmediatamente previos a 1934, el informe afirma que a partir de 1928 la lucha social experimentó "una desviación hacia el bandolerismo" que se manifestaba nuevamente desde 1933 (no realiza mención alguna sobre el año y medio de la dictadura uriburista). Si bien tomaba como muestra los hechos de violencia practicados en 1933-1934 por "comunistas", no argumentaba la fecha elegida como disparador del desviacionismo.

Este aumento de la lucha y del uso de la violencia (esto último remarcado en todo el documento) fue presentado como el motor de la creación de la SERC con Uriburu, creación que continúa según Melo la línea de "acción preventiva" desde la creación de la Sección de Orden Político: "En la República Argentina únicamente existen proyectos y no leyes y esto explica la acción preventiva que en defensa social debe realizar la policía y cuyo frecuente epílogo es la declaración por los jueces de que faltan leyes". ${ }^{12}$ Así, ante las nuevas modalidades de "delincuencia" y de "defensa" del movimiento obrero, se justifica la presencia de la SERC. La acción preventiva debía ocupar el lugar de la falta de regulación de las actividades políticas, en este caso comunistas. En relación a la legislación, Melo señalaba la existencia de una "iniciativa en 1932" que no llegó a ser tratada. La misma no es otra que el proyecto de Ley de Represión al Comunismo realizado por la Comisión Popular Argentina Contra el Comunismo (CPACC, fundada y dirigida por el nacionalista Carlos Silveyra) y por el senador Matías Sánchez Sorondo (ex ministro del interior de Uriburu), que sería presentado por segunda vez en 1936. El objetivo del proyecto era el de declarar como "asociación ilícita" al PC argentino: esta figura criminal ya era empleada por la justicia de esos

12. Mensaje..., folio 51. Ver "Por falta de leyes no puede reprimirse la acción antisocial", La Prensa, año LXV, n 23534, 07/08/1934, p. 12. 
años a la hora de limitar la acción sindical. Un ejemplo de ello fue el proceso realizado al SUOM durante la huelga de junio y julio de $1934 .{ }^{13}$

La SERC era planteada como una necesidad del Estado al nivel de un "sin salida". No haber creado la Sección hubiera sido, en palabras del propio Melo, "lo inexcusable". El documento enfatizaba la relación entre "orden constitucional" y el accionar preventivo de sus fuerzas de seguridad; la actividad de la policía era presentada como la garantía de una estabilidad en reemplazo de una regulación no existente. Así, se remarcaba la diferencia entre "reclamos legitimos" y los actos delictivos o de bandolerismo ligados a esta violencia en ascenso. Las nuevas modalidades que fueron foco de detención por la SERC incluian: resistencia $\mathrm{y}$ ataque a la autoridad, uso de armas de fuego y/o uso de cachiporras contra la autoridad, y formación de grupos de autodefensa por parte de los detenidos. Esta lista comprendía lo que Melo denominaba "actividad comunista", a la que definía como: "La prédica de la violencia como procedimiento para destruir, conculcar las instituciones, infundir el terror y demoler el régimen social existente...". Esto mismo es categorizado por la prensa común como producto de ideas que "atentan contra el orden familiar y social del país", validando de esa manera la acción policial. ${ }^{14}$

"Violencia y atentado contra el orden constituido" se hacen presentes en la caracterización del comunismo. A ello debe agregarse la existencia de una "prédica subversiva", una educación, difusión y propaganda de las estrategias de lucha que eran concebidas como delitos contra el orden constitucional. De esa manera, actos y contenidos vinculados a ese accionar eran elementos fuera de la ley para la policía, logrando de esa manera clasificar a este tipo de actividades como accionar delictivo.

Dentro de estas particularidades del comunismo, el informe agregaba una más: el predominio de extranjeros entre los detenidos. La cuestión de la extranjería fue un elemento presente en el discurso de distintas expresiones reaccionarias de principios de siglo en Argentina como en el escenario abierto por la Gran Guerra, sobre todo en los nacionalistas. Lo extraño a la Nación, a las ideas e instituciones tradicionales, ha sido un tópico recurrente en esas corrientes. En el informe Melo, el discurso

13. Tras un atentado realizado por dos integrantes de ese sindicato y la denuncia por el ataque contra un obrero rompehuelga, la Policía allanó dos locales del SUOM llevando detenidas a más de doscientas personas. Ver "La Justicia considera responsables del delito de asociación ilícita a 220 integrantes de una entidad obrera", en La Prensa, año LXV, n 23503, 07/07/1934, p. 13, y "La Policía allanó los locales de dos sindicatos obreros y detuvo a 220 personas que halló entre ellos", La Nación, año LXV, n 22596, 07/07/34, p. 10 (ello en referencia al SUOM y al CUSC).

14. "Se reprimirán las transgresiones a las leyes penales", en La Nación, año LXIII, $\mathrm{n}^{\circ} 22001,15 / 11 / 32$, p. 1 . 
antiinmigrante o xenófobo se cubría de un manto piadoso que buscaba hablar de "ideas ajenas" o de "malos elementos", dando cuenta del uso de la deportación para combatirlos por medio de la Ley de Residencia. El componente extranjero vuelve a aparecer como conflictivo, pero en este marco eran más las ideas las que corrompian al obrero que la presencia de extranjeros en sí, de ahí que los pliegos redactados por el ministro como el informe policial insistieran en que la acción preventiva debía dirigirse contra esos factores de conflicto pero no necesariamente contra la organización sindical. He aquí la novedad: el documento remarcaba que la policía no sólo debía proteger a la sociedad en general sino además a aquellas organizaciones de trabajadores que "alentados por su sano patriotismo" manifiestan sus reclamos sin necesidad de la violencia.

La Sección analiza que el tipo de accionar que combate era ejercido por militantes ajenos a las organizaciones gremiales conocidas. Para reforzar esta idea rescataba la figura de la CGT que, junto a las organizaciones que representaba, ${ }^{15}$ era separada de esos actos violentos. Merece que incorporemos la postura de la Central, en cuya dirección predominaba la línea sindicalista, frente a la represión. En noviembre de 1933 la misma elevó un comunicado de prensa, en el cual desvinculaba a los obreros de sus organizaciones de los actos violentos reprimidos, ${ }^{16}$ caracterizados como producto del bandolerismo o de internas facciosas y ajenos a las medidas pacíficas de reclamo laboral emprendidas por los gremios de esa confederación. En el mismo comunicado, la CGT explicaba que su lucha era únicamente gremial y contra el fascismo. Además, resaltaba:

Durante la llamada Semana Trágica los militantes obreros eran perseguidos, y recordemos que el Consejo Federal de la Federación Obrera Regional Argentina fue sorprendido y sus participantes llevados al Departamento Central de Policía en un vehículo de la misma. ¿Ha ocurrido ahora un episodio de esa indole? Evidentemente no. Entonces, ¿qué es lo que determinaria al movimiento obrero a sentirse peligrar y apercibirse para luchas cruentas? ${ }^{17}$

En el cierre de su comunicado, la Central insistía que dentro de su lucha contra el fascismo estaba todo atentado a las garantias consti-

15. El documento cita la huelga de la Federación de Obreros y Empleados Telefónicos, organización incorporada a la CGT, como un caso excepcional de empleo de la violencia por parte de un sindicato adherido a esa central. En "Sección Especial", en Mensaje..., folio 65.

16. Confederación General del Trabajo, "Comunicado de Prensa”, 8/11/1933.

17. CGT, “Comunicado...", p. 2. 
tucionales. Ello y su distanciamiento de los "actos violentos" avalaba al informe Melo para considerar la existencia de "verdaderos representantes de la clase trabajadora" (la CGT) en contraposición a quienes "pretendieron mezclar la política en los sindicatos". Por ejemplo, la SERC señalaba las presiones que la central recibió de parte de elementos pertenecientes a "determinado partido político" para participar del llamamiento a una huelga general contra el fascismo que finalmente no fue convocada; podemos suponer que refiere a la fallida huelga general promovida por la FOIC de 1932. Esta defensa de la CGT por el informe policial nos lleva a la pregunta sobre los vínculos mantenidos entre el Estado argentino y los organismos sindicales, en particular aquellos de corriente sindicalista, y cuándo éstos comenzaron a estrecharse.

Esta diferenciación entre aquellos obreros que "cumplian con su deber" (el trabajo y la protesta pacífica) frente a la imagen de quienes promovian la conflictividad como medio de expresar sus reclamos $(\mathrm{u}$ objetivos de mayor trascendencia, como la revolución social), ya había sido realizada previamente. Un caso para referirnos es el de la Asociación del Trabajo, entidad patronal que funcionó desde 1918 hasta finales de la década del 20. Además de recurrir al lock-out o al empleo de grupos de choque o rompehuelgas, esta organización buscó criminalizar acusando de violar el derecho al trabajo libre a los huelguistas (Rapalo, 2012). Esta prerrogativa constitucional es nuevamente citada en los casos de detención por "acciones comunistas" en el informe policial de la Sección. ${ }^{18}$ Suena llamativa, aunque resulta funcional, la denuncia de Melo contra detenidos por actividades comunistas por estar involucrados en la trata de blancas. La cuestión es que el intento por incorporar al "militante comunista" (del PC) dentro del signo delictivo resultaba una práctica cada vez más común en la acción represiva de esos años y una justificación acorde a la buscada "normalidad constitucional".

Así como el informe Melo remarcó la presencia de un nuevo accionar obrero violento y antisocial, también destacó el desarrollo de las estrategias empleadas por los "agentes de desorden social" para poder librarse de la penalidad judicial. La asistencia de abogados especializados en la defensa de detenidos políticos y el respaldo de una organización como el SRI fueron otra preocupación por parte del Estado y sus herramientas represivas. En base a ello, Melo refuerza la hipótesis de un "peligro mayor", no sólo más preparado en materia estratégica y profesional, sino con objetivos y medios claros para obturar el orden y llevar a cabo la temida revolución. ${ }^{19}$

18. "Sección especial", en Mensaje..., folios 85 a 96.

19. En "Fue disperso mitin comunista", en La Nación, año LXIII, n 21874, 11/07/32, p. 24, se relata la interrupción de un mitin del SRI por la Policía en razón del contenido 
La actuación legal de distintos abogados, así como las denuncias del SRI, fueron foco de investigación por la policía. Esto fue incorporado en el informe, principalmente en el apartado reservado para la explicación por las acusaciones de tortura y abusos policiales. Continuando con algunas de las conjeturas iniciales de este trabajo, la actividad del Socorro colaboró con la materialización de la "amenaza comunista", al ser un organismo internacional de asesoramiento legal al servicio de militantes de izquierda.

Como veremos más adelante, el SRI desplegó una campaña contra el gobierno de Justo aduciendo que el mismo continuaba con las mismas prácticas represivas del uriburismo. Estas denuncias acerca del empleo de tortura por parte de la SERC fueron discutidas en el informe, en el cual se acusaba al SRI de emplear las denuncias como un medio de propaganda comunista, con el fin de aumentar la conflictividad y de esa manera lograr la agitación social que permitiera un estallido político. De acuerdo al documento, esas estrategias eran recomendadas por esa organización en su Estatuto, el cual fue adjuntado al informe como evidencia. Varios de sus capítulos, páginas y párrafos se encuentran subrayados, en particular, aquellos en que se recomienda la agitación y propaganda ante el avasallamiento de la represión o, en otros casos, aquellas líneas que vinculan al SRI con la URSS o mencionan a "la lucha internacional":

A páginas 71 en el título IV se indica con claridad el deber de efectuar una persistente agitación contra el sistema carcelario, contra las torturas, trabajos forzados, confinamientos, etc., es decir, da los argumentos a que debe echarse mano para la propaganda... ${ }^{20}$

¿Quiénes eran los intermediarios entre el SRI y los detenidos? De acuerdo al informe, "siempre son los mismos". Los representantes legales que se asociaban a la figura del organismo en cuestión eran Enrique Corona Martínez, Nydia Lamarque, José Katz, José Peco, Rodolfo Aráoz Alfaro y Samuel Smerkin. Aráoz Alfaro, ex socialista y militante del PC en ese entonces, fue uno de los fundadores de la Liga Argentina por los Derechos del Hombre (LADH, heredera de los objetivos y acciones del SRI) en 1937; durante los años 30 se dedicó a presentar recursos de amparo a presos políticos, además de amparar a perseguidos por su militancia de izquierda en su propiedad de Villa del Totoral (Córdoba). Lamarque,

\footnotetext{
"agresivo contra las autoridades" del discurso de uno de los oradores del encuentro, detenido luego.
}

20. Mensaje..., folio 82 . 
si bien fue conocida por su obra literaria, participó como abogada de las querellas en favor de presos políticos del PC en los años 30 y fue de los primeros miembros de la Asociación de Intelectuales, Artistas, Periodistas y Escritores (AIAPE), creada en 1935. Smerkin (o Schmerkin) también participó de la fundación de la LADH junto a Corona Martínez, éste como representante de la Asociación de Abogados de Buenos Aires. De acuerdo al texto de Melo, los letrados mantenían un contacto fluido con los presos, lo que era indicio de la preparación de falsas denuncias y del adiestramiento de los detenidos para la agitación.

En este punto es importante citar la segunda presentación del proyecto de Ley de Represión contra el Comunismo de 1936. En esa oportunidad el senador Sánchez Sorondo presentó un informe que mencionaba a esos mismos abogados como parte de la "ayuda jurídica" del SRI. Este material presentado al Congreso se basó en una extensa investigación de Silveyra que empleó la información de la SERC y que fue publicada en 1936 bajo el título El comunismo en la Argentina (Silveyra, 1936). Así, el objetivo de declarar al comunismo como una actividad criminal (como a aquellos abogados defensores) por parte de Sánchez Sorondo en 1936 encontraba varios de sus justificativos en la lectura que la SERC y el Ministerio del Interior realizaron desde 1932 en adelante.

Como hemos referido, las denuncias sobre los abusos resultaban para el informe invenciones del SRI como parte de una campaña difamatoria contra la institución estatal en un momento en que la Policía de la Capital gozaba de mejoras en sus establecimientos penitenciarios, las cuales el documento cita reiteradamente. Para la policía el ataque contra su institución comprende dos frentes: por un lado, la violencia de los actos delictivos que eran disfrazados de falsas reivindicaciones sociales $\mathrm{y}$, por el otro, la difamación por organismos ligados a ideas ajenas a las tradiciones institucionales y políticas de la Argentina. La relación entre la Unión Soviética y el SRI era motivo de preocupación para el gobierno de acuerdo a su ministro del interior. El SRI se encontraba ligado a un país que llevaba a la práctica la ideología comunista: violencia contra las clases dominantes, socialización de propiedad privada, ateísmo como política de Estado, etc. Sumado a ello, el SRI ensalzaba la figura de la URSS como "ejemplo de país", ${ }^{21}$ lo que es interpretado como la confirmación de la existencia de un plan detrás del "desviacionismo": generar un proceso de desorden institucional que lleve al comunismo. El Socorro resultaba asi el "noviciado rojo" que preparaba y asesoraba

21. "La defensa de la Unión Soviética", en Estatuto del Socorro Rojo Internacional, Barcelona: Ediciones Combate, 1922, p. 62. 
a los partícipes de ese movimiento que motorizaba en la Argentina el PC y a nivel internacional, la URSS. ${ }^{22}$

\section{E1 terror con Justo}

En agosto de 1934 el SRI presentó a la HCD otro mensaje en respuesta al presentado por el ministro Melo, que luego se incorporó en un folleto: Bajo el terror de Justo, que incluyó ese material e información ampliada sobre distintas denuncias de detenidos por la SERC. ${ }^{23}$ El material enviado a Diputados apuntaba a discutir las acusaciones del ministro contra el SRI y analizar el accionar represivo durante la "normalidad constitucional". La posterior publicación de esta investigación tenía como propósito brindar material que la prensa común no ofrecía para los militantes obreros. Bajo el terror de Justo buscaba constituirse como algo más allá de un documento de denuncia: una herramienta para la defensa de los trabajadores.

De acuerdo al SRI, el gobierno de Justo resultaba una extensión de la dictadura uriburista. Con el aparato formal de un régimen democrático, la represión contra el movimiento obrero no sólo se mantenía sino que había recrudecido con nuevos métodos que aplicaban la Policía de la Capital y la SERC. La "normalidad constitucional"

...significó para los trabajadores expulsiones a centenares, confinamientos, deportaciones, encarcelamiento de miles de obreros por tiempo indefinido, persecución y supresión de la prensa obrera, procesos inicuos, anulación del derecho de reunión, anulación del derecho de asociarse, anulación del derecho de huelga, anulación del derecho electoral, anulación del derecho de inviolabilidad de domicilio, del recurso de "habeas corpus", etcétera. ${ }^{24}$

La caracterización de este documento sobre la represión enfatizaba el marco legal que justificaba su aplicación. Podemos concluir que de esa manera tenía lugar una reclasificación de las actividades del movimiento obrero como acciones criminales, lo que nos permite subrayar la idea de una criminalización de la protesta. Por ejemplo, la difusión de propaganda era recategorizada como "instigación a cometer delitos"; ello abarcaba la presencia de panfletos, folletos, boletines y la propia

22. "Sección especial", en Mensaje..., folios 80 y 81.

23. Socorro Rojo Internacional, Bajo el terror de Justo, septiembre-octubre, 1934.

24. Bajo el terror de Justo, p. 15. 
prensa obrera. De ahí que se incorporen al análisis los casos de clausura o supresión de los antes mencionados periódicos comunistas Mundo Obrero, Bandera Roja y Frente Único. A ello vale agregar la aplicación de censura a otras publicaciones en las que participaron miembros del PC, como el caso de Contra. El 26 de septiembre de 1933 la SERC procesó al poeta Raúl González Tuñón por "instigación a la rebelión" a raíz de una poesía publicada en esa revista literaria. Otro caso señalado era el allanamiento a la imprenta que publicaba La Internacional, Soviet, $S R$ e Informaciones, órganos de prensa oficiales del PC en esos años. También se denuncia el establecimiento de una tarifa postal diferencial para las publicaciones periódicas que perjudicó a la prensa obrera, medida tomada por Melo.

"La huelga se ha convertido en un delito" afirmaba el SRI en el apartado sobre la violación de derechos, citando los casos más conocidos de represión violenta contra trabajadores en huelga -como la huelga petrolera de Comodoro Rivadavia en 1932-, subrayando el accionar parapolicial fomentado por el propio gobierno. Esto no era otra cosa que la anuencia a las ligas nacionalistas, caracterizadas por el Socorro como "bandas de asesinos fascistas", acusadas (no se especifica cuál o cuáles de las ligas patrióticas parapoliciales) de atacar a miembros del PC. Las agresiones a militantes anarquistas, socialistas o comunistas eran una acción recurrente en los grupos nacionalistas, quienes interrumpian de forma violenta mítines o celebraciones..$^{25}$ La supresión del derecho a reunión y, en consecuencia, la represión o control de las manifestaciones obreras se suman a la lista de acciones del gobierno. En este marco se incluye el cierre de los locales del SRI, del CUSC, aquellos de la Liga Antiimperialista, de la FORA, entre los más relevantes, quedando sólo los espacios de las bibliotecas obreras como posibles lugares de reunión, también amenazadas por el secuestro o destrucción de material bibliográfico por la policía. Para el SRI, el gobierno de Justo aplicó un "Estado de Sitio permanente" contra la clase obrera. ${ }^{26}$

La "acción preventiva" que Melo describió en su documento fue analizada por el Socorro en su folleto a partir de los medios por los cuales el Estado justificó la detención de militantes "comunistas", como ser las contravenciones y leyes dictadas por la Policía de la Capital. A mediados de 1932 esa institución sancionó un conjunto de edictos contravencionales instalados en "una zona gris entre la ley y el hecho" (Caimari, 2012:

25. Ver "Un mitin ácrata fue interrumpido por elementos nacionalistas y se originó un tiroteo que ocasionó dos víctimas”, en La Prensa, año LXIV, n 22927, 04/11/1932, p. 12, "Sujetos comunistas causaron disturbios en zona céntrica", La Nación, año LXIII, n 21994, 08/11/1932, p. 6.

26. En “iLibertad a los presos sociales!", La Internacional, año XVIII, n 3435 , $11 / 8 / 1934$, p. 1. 
95-100). La regulación y control emanados de este nuevo orden policial permitió que esta fuerza tenga alcance sobre varias dimensiones de la vida cotidiana. Una de las herramientas más empleadas por la policía para la detención fue la figura de "portación de armas", por la que fueron detenidos aquellos que participaban en huelgas, se encontraban distribuyendo panfletos en la vía pública o presenciaban una reunión del PC, cuestiones de las que dio cuenta el informe Melo. Durante la detención, el militante era obligado a firmar una declaración en la que asumía los cargos imputados por la policía. La firma se realizaba bajo amenazas o torturas, o en el caso de las mujeres -que en lo posible no eran agredidas fisicamente- se las obligaba bajo el temor de ser violentadas sexualmente ${ }^{27}$ o de ser acusadas del delito de prostitución. En muchas oportunidades el arresto se extendía más allá de lo que esa contravención especificaba (treinta días) ya que se agregaban nuevas acusaciones a los detenidos. El informe presenta casos relevantes de detenciones por "portación de armas", ${ }^{28}$ en su mayoría ocurridas bajo el ejercicio del estado de sitio, efectuadas o en encuentros vinculados al $\mathrm{PC}$ o en los domicilios de los acusados (ciudad de Buenos Aires, Gran Buenos Aires y ciudad de Córdoba).

Si nos remontamos al informe de la Sección Especial presentada por Melo, entre abril de 1932 a julio de 1934 se realizaron en la ciudad de Buenos Aires treinta casos de "delitos comunistas", resultando 144 los detenidos, además de un conjunto de no identificados, por "instigación a cometer delitos" o daños o atentados. Entre las causas de las detenciones figuraban: incitación al delito, atentado armado contra la autoridad, portación de armas, atentado contra la libertad del trabajo, daños causados por inscripciones o pintadas comunistas, o la venta de rifas calificada como "juego de azar". Como en el informe del Socorro, casi todos los ejemplos tuvieron lugar en mítines o conferencias realizadas por el PC, varios de ellos vinculados a la lucha antifascista. ${ }^{29} \mathrm{El}$ informe de la Sección indicaba que la policía contaba con información sobre el cambio a último momento de sitios donde iban a desarrollarse esos encuentros, lo que indicaría la participación de infiltrados. En relación al uso de armas de fuego, en todos los enfrentamientos entre los agentes represivos y militantes se aduce que estos últimos estaban

27. El ejemplo lo aporta el caso de Clara Spiguelman, ver "Memorial...", Bajo el terror de Justo, pp. 28.

28. Son los de Carlos Barrero, Simón Novik, Esteban Peano, Jesús Manzanelli y Francisco Mónaco.

29. Ver: "Al finalizar un acto antifascista fueron detenidas dos oradoras" en La Prensa, año LXIV, n $22898,5 / 11 / 1932$, p. 13; "Fueron dispersados los asistentes a una reunión comunista", en La Prensa, año LXIV, n 22920, 27/11/1932, p. 12. 
armados o que recurrieron a desarmar a oficiales. El uso de la Ley de Residencia (4.144) también se sumó a los recursos utilizados operando como complemento en los casos de extranjeros. Gran parte de los detenidos terminaron deportados dada su condición de residentes (más de doscientos hasta esa fecha, según el SRI), siendo en la mayoría de los casos refugiados politicos de Italia, Bulgaria o de Bolivia y Paraguay (opositores/desertores de la Guerra del Chaco). Por otro lado, dadas las particularidades del estado de sitio en los meses en que fue aplicado, muchos de los detenidos argentinos habrian corrido el mismo destino. ${ }^{30}$

Finalmente, el informe agregaba el análisis de la situación de los detenidos, dentro de las cuales se incluían el motor de la denuncia en Diputados, las torturas. Las condiciones de las cárceles o comisarias en las que los acusados de "actividades comunistas" pasaban su tiempo de detención (no de condena) eran otro eje de reclamo y de reflejo del maltrato consciente dado al preso político. Allí citaban el tamaño de las celdas correspondientes a los aprehendidos por la SERC: el cuadro X del penal de Devoto, la Comisaría nro. 8 anexa a los calabozos de la SERC (podemos conjeturar que fue un edificio dependiente de esa comisaria el que fue destinado a la Sección) y el cuadro V del Departamento Central de la Policía de la Capital. A la falta de luminosidad y de higiene se sumaba la ausencia de camas y de asistencia médica adecuada. Esta descripción se acompañaba de citas sobre el maltrato a los visitantes, sean familiares, ${ }^{31}$ amigos o los propios abogados del Socorro. Tema aparte corresponde al trato hacia las mujeres, en el que se incluía la violencia sexual como así su detención en las mismas celdas de las detenidas por prostitución, siendo esta última cuestión fuertemente criticada por el SRI. Dentro de esto se introdujo la denuncia del nacimiento de un niño en medio del período de detención de su madre, ambos permaneciendo bajo presidio en la SERC.

La tortura que la SERC ejercía contra sus detenidos fue varias veces citadas por distintos trabajos. El clásico de Rodríguez Molas (1985) analiza la aparición de estas técnicas de tortura en la SOP para el ciclo de Uriburu; sin embargo no contempla la existencia de la SERC aunque anuncia a Justo como un "perfeccionador" de la de Orden Político. Hernán Camarero (2007) presenta las actividades de la SERC como parte del despliegue de un anticomunismo "multiforme", en el que la tortura

30. En “¡El ministro Melo miente!”, Revista del Socorro Rojo Internacional, agostoseptiembre de $1934, \mathrm{n}^{\circ} 13$, p. 7.

31. Un ejemplo es el de los familiares de los detenidos del SUOM, quienes en una oportunidad fueron impedidos de realizar su visita en el Departamento Central de Policía, lo que provocó incidentes entre oficiales, visitantes y presos. En "Varios procesados hicieron desorden en el Departamento de Policía", La Prensa, año LXV, $\mathrm{n}^{\circ}$ 23509, 13/07/1934, p. 13. 
sistemática impartida por la Sección formaba parte de la escalada represiva estatal. El folleto del SRI arriesgaba que los torturados de la SERC se acercaban al número de quinientas personas para 1934. Se afirmaba, por otra parte, que la aplicación de los tormentos se había transformado en una técnica con jerga propia: "La técnica va desde el "punching" boxísitico (1), a la "picana eléctrica" (2), pasando por "los palillos" (3) la prensa (4), la "escalera" (5), el "gallo ciego" (6), la "corona" (7), el "ahorcamiento" (8), el narcótico (9), etc.". ${ }^{32}$

El texto cuenta con dieciocho testimonios sobre la aplicación de tortura. Entre ellos aparecen el de José Peter, obrero de la carne y cabeza de la FOIC; Antonio Cantor, que había sido dirigente de la Federación Juvenil Comunista en 1922; el de otros militantes obreros como Robustiano Sáez, albañil, y Lázaro Dain, empleado con residencia en Córdoba; también el de extranjeros como Carlos Barrero, Vicente Nardille, italianos, los búlgaros Pedro Angeloff (portuario) y Stoian Teodoroff (peón); de detenidos por poseer un folleto del PC o de la Internacional Comunista como Pedro Marino; y el del estudiante Rodolfo César Cañete. La mayoría de los nombrados continuaban presos para la fecha de la presentación del pliego a Diputados, así como habían tenido fallas cardíacas y enfermedades pulmonares a raíz de los tormentos. Resulta llamativo que sean pocos los testimonios que acreditan que la aplicación de tortura se realizaba con el fin de extraer información del detenido. La mayoría de los casos describe los tormentos sufridos como si fuesen parte de la cotidianeidad del encarcelamiento, no necesariamente para "arrancar confesiones", como señalan Camarero (2007) y Rodríguez Molas (1985). ¿La tortura tenía un fin o era un fin en sí mismo ya para ese entonces? ¿La criminalización implicaba un sometimiento del detenido "comunista" y por ende un merecido castigo ejemplar?

La connivencia del Poder Judicial aparece finalmente como un eslabón de la cadena represiva. Acusándolo de complicidad, el SRI cita casos de jueces comunes que, al desestimar querellas o recursos de habeas corpus de abogados defensores, se contradecian en los argumentos dados en sus condenas. Además, algunos de los jueces participaron del hostigamiento a los abogados defensores, queriendo incriminarlos por realizar la defensa de militantes comunistas. Entre los jueces mencionados aparece la figura de Miguel Jantus, juez a cargo del procesamiento de González Tuñón; en 1935 la AIAPE lo denunció, acusándolo de cercenar el desarrollo cultural y la libertad de expresión (Deves, 2013). Tanto Jantus como el Juez en lo Criminal Antonio Berutti (no mencionado en el informe) participaron en los primeros años de la década en allanamientos a sindicatos e intentos de declarar como "asociación

32. Bajo el terror de Justo, p. 44. La numeración es del original. 
ilícita" a distintas organizaciones obreras. Finalmente se resalta la falta de investigación por parte de los juzgados de Instrucción y Crimen de la Capital Federal, señalando nuevamente Jantus y a los jueces Ceballos, Speroni y al juez platense Cotti de la Lastra por sus arbitrarias condenas a trabajadores acusados de "actividades comunistas", entre las cuales figura una condena a un obrero sin trabajo por considerar que los desocupados son "un peligro para la tranquilidad y seguridad de las personas". Otra cuestión, esta vez citada en el apartado sobre las torturas, es la ausencia en las declaraciones tomadas por los juzgados a los presos de información sobre las condiciones de detención y la situación física de los torturados.

$$
* * *
$$

El reclamo del PS por el accionar de la SERC de 1934 finalizó de manera silenciosa con el informe presentado por Melo y con ello su debate. La Sección Especial, las detenciones bajo el rótulo de "actividades comunistas" y las torturas continuaron durante toda la década de 1930. Dos años más tarde, la "cuestión comunista" volvió a hacerse visible tras las consecuencias de la huelga de los obreros de la construcción de 1936 y la segunda presentación del proyecto de Ley de Represión al Comunismo. Sin embargo el "informe Melo" no fue mencionado en esa oportunidad.

¿Qué aporta nuestro análisis para el escenario de los años 30? Por un lado, el material del Ministerio del Interior y la Policía de la Capital dan cuenta del avance del aparato estatal en materia represiva y la justificación de ello en la concepción de "acción preventiva" ante la ausencia de herramientas que desde la legalidad formalizaran el control. El informe buscaba dejar en claro la posición del gobierno en relación a las corrientes radicalizadas del movimiento obrero: eran criminales y no hay negociación. Mientras, otros sectores, como los nucleados en torno a la CGT de dirección sindicalista, eran aceptados e incorporados al juego político planteado por el Estado. Pocos años más tarde, el inicio de la intervención en conflictos laborales por medio de los Departamentos de Trabajo emergió como un complemento de la represión. Cabe preguntarnos qué variantes introdujeron ese nuevo accionar por el Estado, aunque muy probablemente la respuesta se halle una vez más en las estrategias del movimiento obrero.

Lo que evidenciamos en esta "muestra" de la dimensión práctica del anticomunismo es la relación entre actores por lo general analizados de forma aislada: anticomunistas/antiizquierdistas frente a las izquierdas del movimiento obrero/comunistas. La acción preventiva planteada emergió a raíz de las nuevas modalidades de una clase trabajadora en 
reorganización que ya hace uso de la representación legal para ampararse ante los abusos del Estado. Desde la SERC, la represión (el Estado) "leyó" esas estrategias y apuntó a las mismas por medio de un entramado complejo que fue conformando un sistema: contravenciones, leyes, actuación del Poder Judicial, investigación e inteligencia, detenciones, torturas, forman parte de una reorganización de la función disciplinaria estatal realizada por el gobierno conservador. Esa estructura permitió reclasificar a parte del movimiento obrero y sus prácticas como "disolventes" en contraposición a la idea de reclamos "legitimos" de otro sector de la clase trabajadora.

Por otro lado, organizaciones como el PC dieron lugar a la imagen de un "peligro rojo" concreto: un partido con estrategias y organizaciones políticas y culturales, en enfrentamiento violento contra las fuerzas del orden y con un organismo internacional de asesoramiento legal a su servicio. Ello reforzó una dicotomía ya existente en el pensamiento de los nacionalistas reaccionarios, en particular gracias a la operación de "criminalizar" a los trabajadores cuyos métodos apelaban a la violencia o incluian en su discurso el elemento internacionalista. Esto nos sugiere que el gobierno conservador del ciclo 1932-1943 se nutrió de ese análisis realizado por los actores del nacionalismo, lo que implica plantear una unión entre la dimensión práctica que analizamos en este trabajo y la ideológica. ¿Acaso esta ideología y práctica que conocemos como anticomunismo no logró su mayor despliegue cuando esas dos dimensiones coincidieron? Un estudio completo del caso queda pendiente cuando avancemos sobre ese discurso, complemento perfecto de la política represiva de Estado.

Queda por concluir que el Estado argentino de los años 30 pudo encerrar dentro de su "cuestión comunista" una forma de disciplinamiento político. Eso implicó una estructura de represión y una calificación para el conflicto obrero y sus actores protagonistas basadas en una lectura reaccionaria de las transformaciones que el movimiento sindical estaba desplegando en ese entonces. Alejados ya del falaz "anticomunismo sin comunismo" de Rouquié y Zanatta, podemos cerrar preguntando si esta estrategia represiva sentó las bases de una política a largo plazo. Creemos que ella se mantuvo presente junto a otras herramientas de negociación que con los años se irian desplegando.

\section{Bibliografia}

Caimari, Lila (2012), Mientras la ciudad duerme. Pistoleros, policías y periodistas en Buenos Aires, 1920-1945, Buenos Aires: Siglo XXI.

Camarero, Hernán (2007), A la conquista de la clase obrera. Los comunistas 
y el mundo del trabajo en la Argentina, 1920-1935, Buenos Aires: Siglo XXI.

Ceruso, Diego (2010), Comisiones internas de fábrica. Desde la huelga de la construcción hasta el golpe de estado de 1943, Buenos Aires: PIMSADialectik.

Del Campo, Hugo (1983), Sindicalismo y peronismo. Los comienzos de un vínculo perdurable, Buenos Aires: Siglo XXI.

Deves, Magali (2013), "Por la defensa de la cultura: Arte y política en las publicaciones de la AIAPE", en Jornadas Internacionales y IV Nacionales de Historia, Arte y Politica, Buenos Aires.

Devoto, Fernando (2002), Nacionalismo, fascismo y tradicionalismo en la Argentina moderna, Buenos Aires: Siglo XXI.

Finchelstein, Federico (2010), Fascismo transatlántico. Ideología, violencia y sacralidad en Argentina y en Italia, 1919-1945, Buenos Aires: Fondo de Cultura Económica.

Horowitz, Joel (2001), "El movimiento obrero", en Nueva historia argentina, 1930-1943, vol. VII, Buenos Aires: Sudamericana.

Iñigo Carrera, Nicolás (2000), La estrategia de la clase obrera, 1936, Buenos Aires: PIMSA-La Rosa Blindada.

- (2002), La huelga general politica de 1932: descripción de los inicios de un ciclo en la historia de la clase obrera argentina, Buenos Aires: PIMSA, Documentos e Investigaciones 2001.

Kalmanowiecki, Laura (1991), Military Power and Policing in Argentina 19001955, tesis doctoral, mimeo.

Korzeniewicz, Roberto (1993), "Los conflictos laborales entre 1930 y 1943", Desarrollo Económico, vol. 33, n ${ }^{\circ} 131$.

Lvovich, Daniel (2003), Nacionalismo y antisemitismo en la Argentina, Buenos Aires: Vergara.

Matshushita, Hiroshi (1983), Movimiento obrero argentino, 1930-1945. Sus proyecciones en los orígenes del peronismo, Buenos Aires: Siglo Veinte.

McGee Deutsch, Sandra (2005), Las derechas. La extrema derecha en la Argentina, Brasil y Chile 1890-1939, Bernal: UNQ.

Rapalo, María Ester (2012), Patrones y obreros. La ofensiva de la clase propietaria, 1918-1930, Buenos Aires: Siglo XXI.

Rock, David (1993), La Argentina autoritaria, Buenos Aires: Ariel.

Rodríguez Molas, Ricardo (1985), Historia de la tortura y el orden represivo en la Argentina, Buenos Aires: Eudeba.

Rouquié, Alain (1978), Poder militar y sociedad politica en la Argentina, tomo I, Buenos Aires: Emecé.

Silveyra, Carlos (1936), El comunismo en la Argentina, Buenos Aires: Patria.

Ubertalli, José Luis (2010), El enemigo rojo. La represión al comunismo en la Argentina, Buenos Aires: Acercándonos.

Zanatta, Loris (1996), Del Estado liberal a la Nación católica. Iglesia y Estado en los orígenes del peronismo, 1930-1943, Bernal: UNQ. 


\section{$* * *$}

Resumen: El presente artículo toma como centro al debate de 1934 sobre la Sección Especial de Represión al Comunismo. Con el fin de analizar la existencia de una "cuestión comunista" en el Estado argentino de ese entonces se abordan dos documentos clave: el informe del Ministerio del Interior sobre la actividad de la Sección Especial, y el documento-denuncia del Socorro Rojo Internacional acerca de la represión política del gobierno de Agustín P. Justo. En base a ello, nos proponemos comprender cómo el aparato estatal empleó la criminalización de las actividades políticas de una parte del movimiento obrero y de otros actores con el fin de ampliar el control sobre la clase trabajadora en el escenario de los años 30 .

Palabras clave: movimiento obrero - represión - anticomunismo - entreguerras

Abstract: The objective of this paper is an survey of 1934's political debate surrounding the Police Special Branch for the Repression of Communism. With the purpouse of analysing the existence of a "Communist Problem" at that time in the Argentinean State two key documents shall be addressed: the report on the activities of the Special Branch issued by the Ministry of Interior; and Socorro Rojo International's complaint on the political repression of the Agustin P. Justo administration. On this basis we shall strive to comprehend how the criminalization of the political activities of part of the labor movement, and other related actors, was employed by the state apparatus as a means to extend it's control of the working classes during the 30 s.

Keywords: labor movement - repression - anticommunism - interwar period

Recepción: 3 de octubre de 2013. Aprobación: 29 de diciembre de 2013. 